\title{
Cell therapy with autologous mesenchymal stromal cells in post- traumatic syringomyelia
}

\author{
JESÚS VAQUERO ${ }^{1}$, MERCEDES ZURITA $^{1}$, MIGUEL A. RICO $^{1}$, CONCEPCION AGUAYO $^{1}$, \\ CECILIA FERNANDEZ ${ }^{1}$, GREGORIO RODRIGUEZ-BOTO ${ }^{1}$, ESPERANZA MARIN ${ }^{2}$, \\ NOEMI TAPIADOR ${ }^{3}$, MARTA SEVILLA $^{3}$, JOAQUIN CARBALLIDO ${ }^{4}$, DAVID VAZQUEZ ${ }^{4}$, \\ DAMIAN GARCIA-OLMO ${ }^{5}$, HECTOR GUADALAJARA ${ }^{5}$, MIGUEL LEON ${ }^{5}$, \\ IGNACIO VALVERDE ${ }^{5}$ \& THE NEUROLOGICAL CELL THERAPY GROUP FROM \\ PUERTA DE HIERRO-MAJADAHONDA HOSPITAL *
}

\author{
${ }^{1}$ Neurosurgery Service, University Hospital Puerta de Hierro-Majadahonda, Autonomous University, Madrid, Spain, \\ ${ }^{2}$ Clinical Neurophysiology Service, University Hospital Puerta de Hierro-Majadahonda, Autonomous University, \\ Madrid, Spain, ${ }^{3}$ Rehabilitation Service, University Hospital Puerta de Hierro-Majadahonda, Autonomous University, \\ Madrid, Spain, ${ }^{4}$ Urology Service, University Hospital Puerta de Hierro-Majadahonda, Autonomous University, \\ Madrid, Spain, and ${ }^{5}$ Service of Coloproctology, Hospital General de Villalba, Madrid, Spain
}

\begin{abstract}
Background aims. Recently, clinical studies show that cell therapy with mesenchymal stromal cells (MSCs) improves the sequelae chronically established in paraplegic patients, being necessary to know which of them can obtain better benefit. Methods. We present here a phase 2 clinical trial that includes six paraplegic patients with post-traumatic syringomyelia who received 300 million MSCs inside the syrinx and who were followed up for 6 months. Clinical scales, urodynamic, neurophysiological, magnetic resonance (MR) and studies of ano-rectal manometry were performed to assess possible improvements. Results. In all the cases, $M R$ at the end of the study showed a clear reduction of the syrinx, and, at this time, signs of improvement in the urodynamic studies were found. Moreover, four patients improved in ano-rectal manometry. Four patients improved in neurophysiological studies, with signs of improvement in evoked potentials in three patients. In the American Spinal Injury Association (ASIA) assessment, only two patients improved in sensitivity, but clinical improvement in neurogenic bowel dysfunction was observed in four patients and three patients described improvement in bladder dysfunction. Spasms reduced in two of the five patients who had them previous to cell therapy, and spasticity was improved in the other two patients. Three patients had neuropathic pain before treatment, and it was reduced or disappeared completely during the study. Only two adverse events ocurred, without relation to the cell therapy. Conclusions. Cell therapy can be considered as a new alternative to the treatment of post-traumatic syringomyelia, achieving reduction of syrinx and clinical improvements in individual patients.
\end{abstract}

Key Words: cell therapy, mesenchymal stromal cells, paraplegia, post-traumatic syringomyelia, spinal cord injury

\section{Introduction}

At present, cell therapy with autologous mesenchymal stromal cells (MSCs) seems to be a therapeutic promise for patients with established spinal cord injury (SCI), but these techniques are still subject to uncertainties related to the disparity of protocols and subject selection. When cell therapy is applied to patients with SCI, a strategy may be the intralesional or intrathecal administration of MSCs. This type of cell therapy is safe and effective for patients with chronic paraplegia $[1,2]$. However, if MSCs are administered into a great cavity, the possibility that transplanted cells die by a mechanism of anoikis [3], as an apoptotic response to the

${ }^{\star}$ A complete list of the investigators (Neurological Cell Therapy Group from Puerta de Hierro-Majadahonda Hospital) is provided in the Supplementary material.

Correspondence: Jesús Vaquero, $\mathrm{MD}$, PhD, Neurosurgery Service, University Hospital Puerta de Hierro, Majadahonda, Autonomous University, Manuel de Falla, 1, Majadahonda 28222, Madrid, Spain. E-mail: jvaqueroc@telefonica.net 
absence of cell-matrix interactions, must be taken into account. The present clinical trial studies if, in the case of paraplegic patients with extensive syringomyelia, some type of clinical improvement can be expected after MSC administration or if these patients should be excluded from any attempt at improvement. Thus, in the present article we show the experience obtained with a phase 2 clinical trial (EudraCT: 2015-002383-16; Clinical Trials.gov NCT02807142), which includes six patients with chronic paraplegia and an extensive posttraumatic syringomyelia.

\section{Methods}

\section{Cell therapy medicament}

We used a cell therapy medicament (NC1) developed after pre-clinical studies by our group and currently approved as a medicament under clinical investigation (PEI number 12-141) by the Spanish Agency of Medicament and Health Products (AEMPS). This medicament consists of autologous MSCs and autologous plasma as its excipient. Previous to medicament preparation, a sample of peripheral blood was retrieved from each patient for genomic studies to rule out chromosomal abnormalities that could discourage cell expansion and to obtain a genetic fingerprint (KaryoNIM Stem Cells and KaryoNIM STR test, respectively; NIMGenetics).

Data about the cell therapy medicament, including genetic studies, culture, formulation, packaging and phenotypic characterization of the MSCs, are provided in the Supplementary Material (Supplementary Figure S1).

\section{Study design and treatment}

The clinical trial protocol was approved by the ethics committee of Puerta de Hierro-Majadahonda Hospital and by the AEMPS. It was conducted in accordance with the principles of the Declaration of Helsinki [4] and good clinical practice guidelines [5]. A flow chart of the patients can be seen in Supplementary Material (Supplementary Figure S2). Adverse events were collected throughout the follow-up and classified according to the Medical Dictionary for Regulatory Activities (MedDRA version 18.1).

This clinical trial included six male patients. Age ranged between 30 and 50 years (mean \pm standard deviation [SD], $39 \pm 7.6$ years). The time elapsed from the SCI until the moment of initiating the cell therapy ranged between 5.75 and 27.68 years (mean \pm SD, $13.73 \pm 8.65$ years). According the American Spinal Injury Association Impairment Scale (AIS), three patients $(50 \%)$ were American Spinal Injury Association (ASIA) A, two patients (33.3\%) were ASIA B and one patient $(16.6 \%)$ was ASIA D. With regard to the level
Table I. Clinical data of the patients.

\begin{tabular}{lllllll}
\hline Patient code & 01 & 02 & 03 & 04 & 05 & 06 \\
\hline Age (y) & $\mathbf{3 0}$ & $\mathbf{5 0}$ & $\mathbf{4 3}$ & $\mathbf{3 8}$ & $\mathbf{4 2}$ & $\mathbf{3 1}$ \\
Time since SCI (y) & $\mathbf{5 . 7 5}$ & $\mathbf{2 7 . 6 8}$ & $\mathbf{1 7 . 0 1}$ & $\mathbf{6 . 1 6}$ & $\mathbf{1 7 . 7 2}$ & $\mathbf{8 . 0 7}$ \\
Vertebral level & D3 & D8 & L1 & D5 & D4 & D5 \\
AIS grade & A & A & D & B & B & A \\
\hline
\end{tabular}

of SCI, two patients (33.3\%) had the lesion at D5 level, and the remaining four patients had the level of SCI at D3, D4, D8 and L1, respectively (Table I).

In magnetic resonance (MR), all of the patients had a large syringomyelic cavity on either side of the SCI area. In length, the extension of the syrinx ranged between 87 and $300 \mathrm{~mm}$ (mean $\pm \mathrm{SD}$, $210.3 \pm 90.94 \mathrm{~mm})$. In the medium sagittal plain, the width of the syrinx ranged between 10 and $20 \mathrm{~mm}$ (mean $\pm \mathrm{SD}, 12.05 \pm 3.97 \mathrm{~mm}$ ). The measurements were taken by means of software associated with MR3T equipment (Philips Intera Achieva XR, v 263.9; Philips Healthcare) on sagittal T2-weighted images and MR-myelography images achieved with sequences of "turbo spin-echo".

Treatment consisted in the administration, inside of the syrinx, of $300 \times 10^{6}$ autologous expanded MSCs, supported in autologous plasma (month 1 of the study; Supplementary Figures S3, 4 and 5). The patients were followed up until month 6 .

Clinical scores were obtained from each patient by means of the following scales: the scale provided by the ASIA [6], the SCI functional rating scale of the International Association of Neurorestoratology (SCI Functional Rating Scale of the International Association of Neurorestoratology [IANR-SCIFRS] scale) [7], the Visual Analog Scale (VAS) for the evaluation of neuropathic pain [8], the Penn [9] and the modified Ashworth [10] scales for the evaluation of spasms and spasticity, respectively, the Geffner scale [11] for the study of bladder function and the scale described by Krogh et al. [12] for the study of neurogenic bowel dysfunction (NBD). MR and studies of neurophysiology, urodynamic and ano-rectal manometry were also performed before and after the treatment. Additional details are provided in the Supplementary Material.

\section{Statistical analysis}

To study the differences between the scores of the clinical scales, the nonparametric Wilcoxon rank test has been used, comparing the result of each time period with results at baseline. Descriptive analysis was performed for urodynamic, neurophysiological and anorectal manomety parameters. Safety analysis was analyzed by means of frequencies and percentages. The graphs were made with the GraphPad Prism program 
Table II. Different scores in ASIA scale.

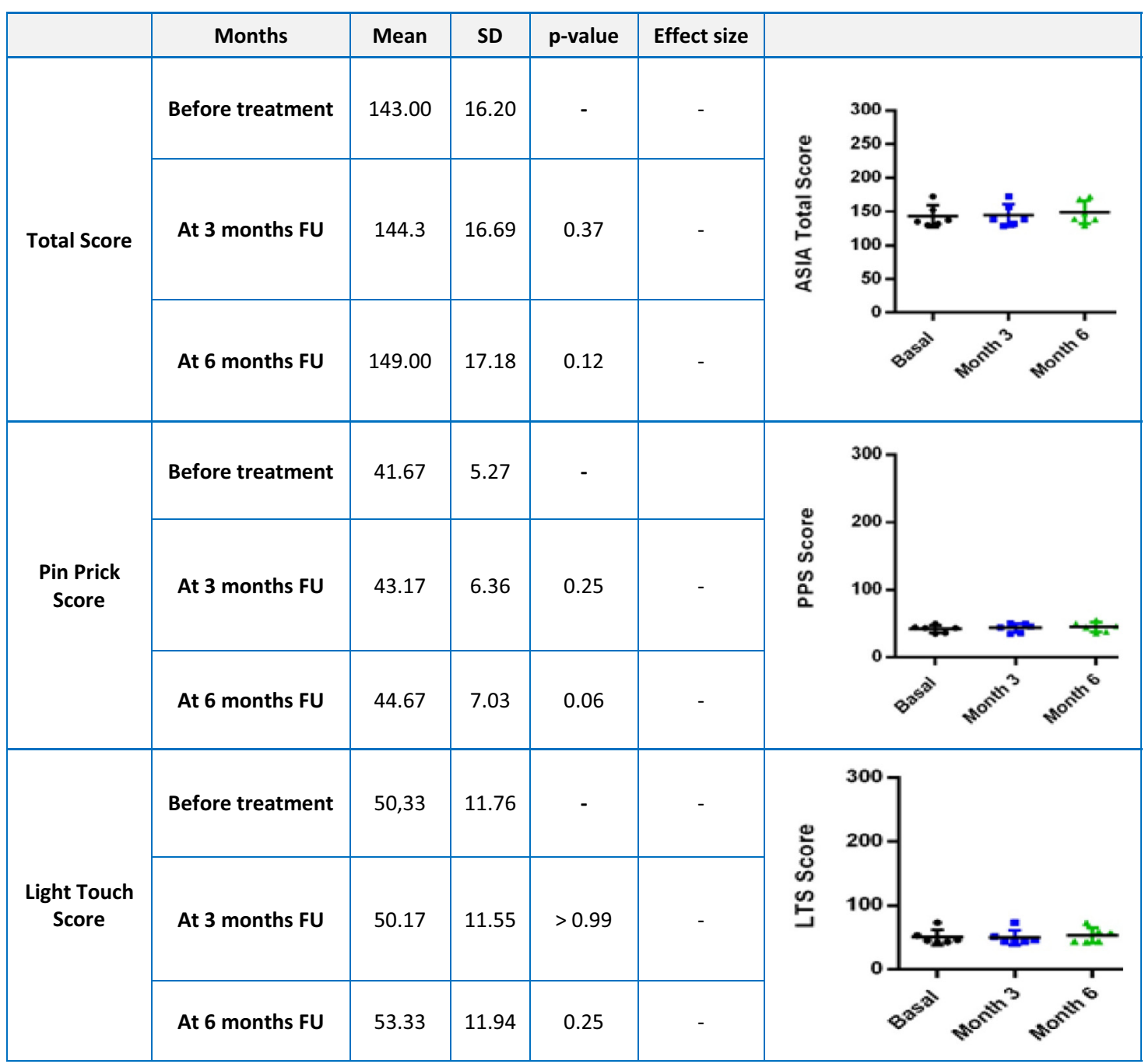

Wilcoxon test was applied comparing each month with baseline. Tendency to improvement was observed but without statistical significance.

FU, follow-up.

for Windows (version 5.04; GraphPad Software). All inferential procedures used $\alpha=0.05$ as the level of risk.

\section{Results}

In our present clinical trial, the cell expansion process did not involve any alteration to the genome of the cells in any of the cases, according to the results obtained after analysis by the Array-comparative genomic hybridization platform.

\section{Adverse events}

During the study, two patients suffered some type of adverse event (AE); patient 02 had an episode of bronchopneumonia and patient 04 had accidental burns on the legs. In both cases, these AEs had no relationship with the treatment.

\section{Sensitivity and motor assessment}

Sensitivity and motor assessments, according to the ASIA scale, did not show changes in motor scores during the follow-up in any of the patients. In sensitivity, only two patients showed improvement. Patient 02 changed the light touch score from 46 (baseline and at the third month) to 59 at the end of the study. Patient 03 changed the light touch score from 53 (baseline) to 57 at the end of the study, and the pin prick score from 43 (baseline) to 50 at the third month and to 55 at the end of follow-up. The statistical study failed to obtain significant differences between sensitivity scores at the end of the follow-up compared with the pre-treatment scores $(P=0.25$ in light touch score assessment, and $P=0.06$ in pin prick score assessment). Table II shows the scores of sensitivity obtained in the ASIA scale previous to treatment, at the third month 
Table III. Scores in IANR-SCIFRS scale.

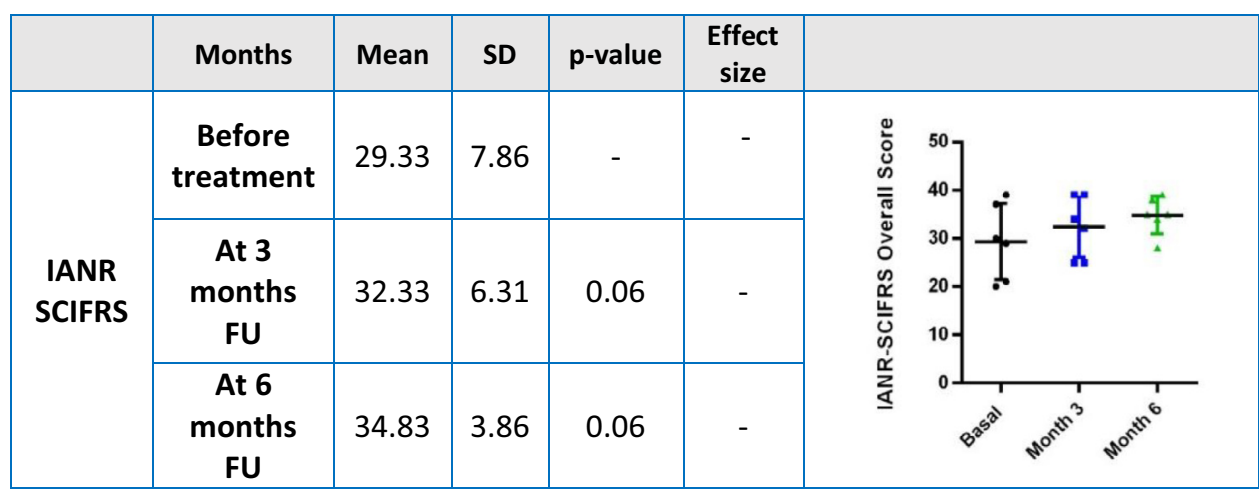

Wilcoxon test was applied comparing each month with baseline. Tendency to improvement was observed but without statistical significance.

after MSC administration and at the end of the followup (month 6).

\section{Spinal cord function assessed using the IANR-SCIFRS scale}

The IANR-SCIFRS scale evaluates the global spinal cord function through nine sections, with a final section that only applies to men and assesses sexual function. When statistical study was performed, the average score in IANR-SCIFRS before treatment was 29.33 points (SD, 7.86 points), and, at the end of the study, it was 34.83 points (SD, 3.86 points), showing a tendency to improvement, but without statistical significance ( $P=0.06$ at the third and sixth months; Table III).

The assessment of sexual function, according to the IANR-SCIFRS scale, failed to show improvement in any of the patients.

At the end of follow-up, the two patients who showed improvement in sensitivity in the ASIA assessment reported better sphincter function in the evaluation of the IANR-SCIFRS, which evaluates from 0 to 6 points this parameter (patient 02 changed from 0 to 2 points, and patient 03 changed from 0 to 3 points).

According to the analysis of global IANR-SCIFRS scale, two patients showed a "slight handicap," before treatment, and four patients showed a "medium handicap," while, at the end of the follow-up, five patients showed a "slight handicap" and the remaining patient showed a "medium handicap" (Figure 1).

\section{Spasms and spasticity}

Previous to cell therapy, all the patients showed variable degree of spasms and/or spasticity measured using the Penn and Ashworth scales, respectively. In four patients, these manifestations improved during the treatment, but no differences with statistical significance were found. Tables IV and V show the tendency to improvement in spasms (Penn scale) and spastic- ity (Ashworth scale) but statistical analysis between scores before treatment and at the end of follow-up failed to obtain significance $(P=0.50)$.

\section{Neuropathic pain}

Prior to cell therapy, neuropathic pain, measured using the VAS scale, was present in three patients. In all of them, it decreased or disappeared completely during the time of follow-up. Table VI shows the evolution in the scores of neuropathic pain measured using the VAS scale, with a tendency to improvement, but statistical analysis between scores before treatment and at 6-month time points failed to obtain significance $(P=0.25)$.

\section{Effect of cell therapy on bladder and bowel dysfunction}

We analyzed the posible clinical improvement of bladder and bowel dysfunction using the scales of Geffner and NBD, respectively. In the Geffner scale (Table VII), which values bladder function, improvement was observed in three patients, but statistical analysis failed to obtain significant differences between scores at the end of the follow-up compared with the pre-treatment scores $(P=0.25)$.

In the NBD scale, which values neurogenic bowel dysfunction, improvement was also observed in four patients, but statistical analysis failed also to obtain significant differences between scores at the end of the follow-up compared with the pre-treatment scores $(P=0.12$; Table VIII).

When the NBD rating scale was analyzed, we observed that previous to cell therapy, one patient had a very minor NBD, one patient had a minor NBD, one patient had a moderate NBD and three patients had a severe NBD. At 3 months of follow up, two patients had a very minor NBD, one patient had a minor NBD, two patients had a moderate NBD and one patient had a severe NBD. At the end of the follow-up, three patients had a very minor 


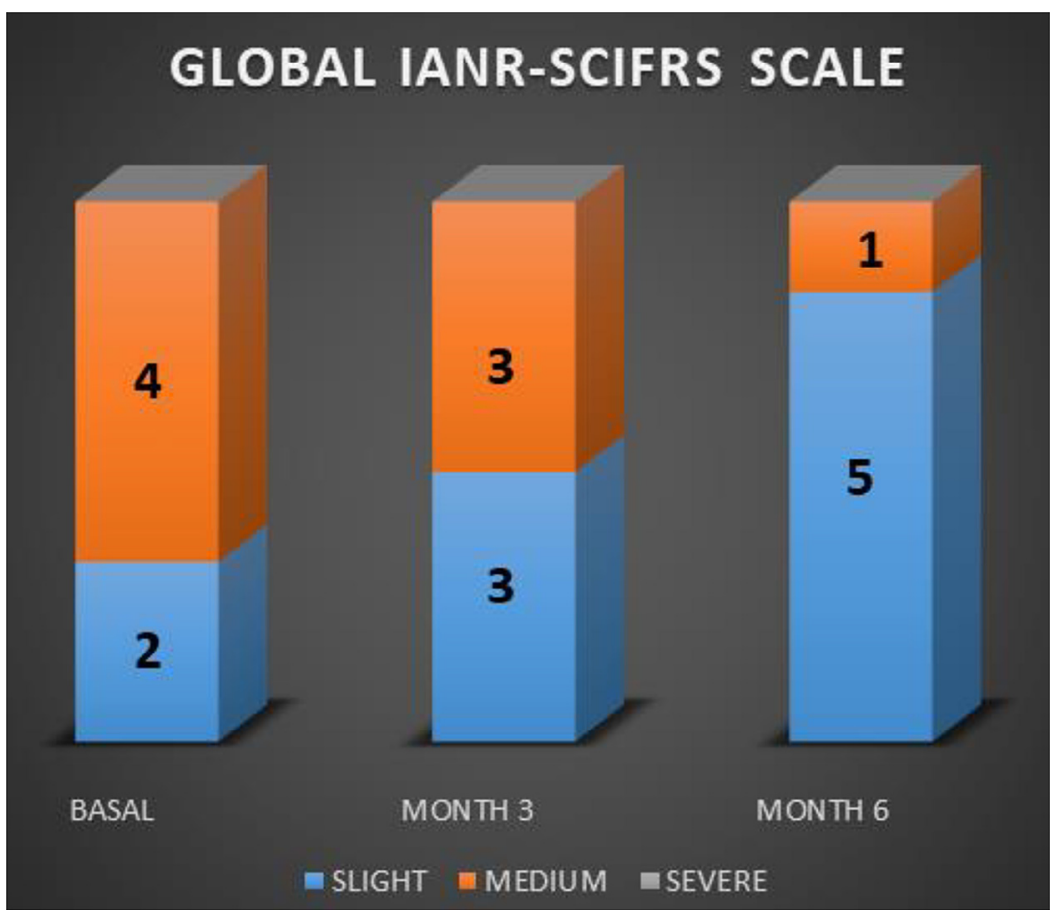

Figure 1. Improvements of patients in the IANR-SCIFRS scale. Previous to cell therapy, two patients had a slight handicap and four patients had a medium handicap. At the end of the study, five patients had a slight handicap and one patient had a medium handicap.

NBD, one patient had a minor NBD, one patient had a moderate NBD and one patient had a severe NBD (Figure 2).

\section{Studies of ano-rectal manometry}

Table IX shows the improvement obtained for each patient in the studies of ano-rectal manometry. In comparison with the baseline study, at the end of the follow-up, four patients showed improvement either in sensitivity (first sensation at filling) or achieving a higher pressure in anal contraction or higher pressure of rectal sphincter at rest. Additional information is provided in the Supplementary Material (Supplementary Table S1).

\section{Urodynamic studies}

At the end of the study, all of the patients improved in some urodynamic parameters, in comparison with the studies carried out previous to administration of cell therapy. Table $\mathrm{X}$ shows the improvements obtained for each patient. At the end of the study, four patients improved in first sensation at filling, four patients improved in maximum cystometric capacity, three patients showed decrease in detrusor pressure at filling and four patients improved in postmictional residue. Furthermore, three patients improved in bladder compliance. Additional information is provided in the Supplementary Material (Supplementary Table S2).

Table IV. Scores in Penn scale.

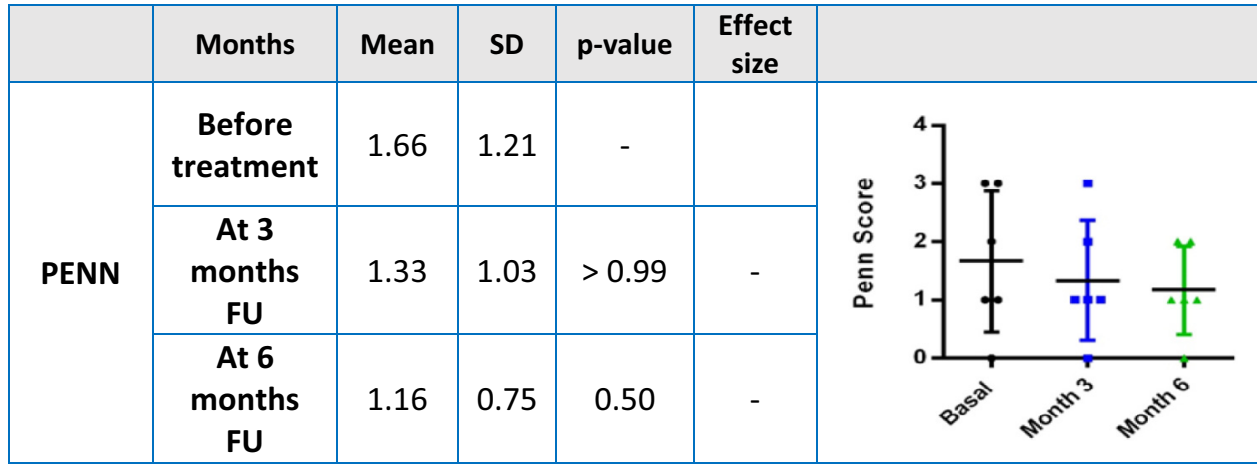

Wilcoxon test was applied comparing each month with baseline. Tendency to improvement was observed but without statistical significance. 
Table V. Scores in Ashworth scale.

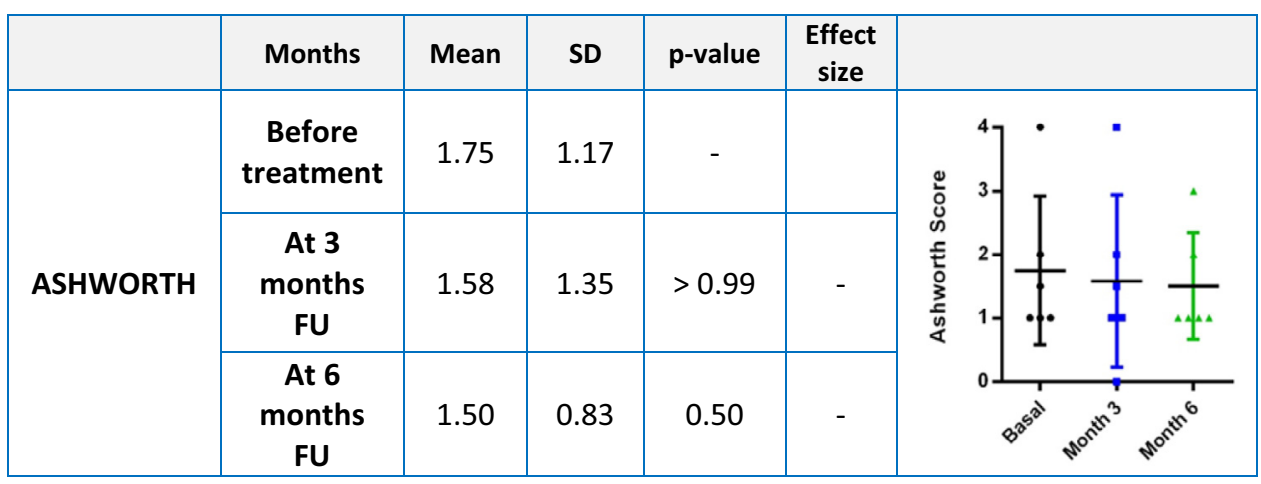

Wilcoxon test was applied comparing each month with baseline. Tendency to improvement was observed but without statistical significance.

\section{Neurophysiological studies}

Neurophysiological improvements were obtained in four patients. In comparison with the neurophysiological studies performed previous to cell therapy, at the end of follow-up, improvement in somatosensory evoked potentials, in latency and/or amplitude, was recorded in two patients. One patient improved in motor evoked potentials. Two patients improved in sensitive nerve conduction, and one patient improved in motor nerve conduction. Furthermore, at the end of the study, one patient showed improvement in voluntary muscle contraction, and two patients showed electromyographical signs of infralesional active muscle reinnervation. Table XI shows the improvement for each patient in neurophysiological studies.

\section{Neuroimaging studies}

In all of the cases, MR performed at the end of followup showed a decrease in the length and/or width of the syrinx. The measurements were obtained by means of the software associated with the imager, and they must be considered as approximate due to the difficulty of obtaining strictly superimposable images in sequential studies. Although a decrease in length and width of syrinx was observed at the end of followup, statistical sigificance was only found for the changes in syrinx width $(P=0.003)$. When the syrinx/canal index was studied, as an index that indirectly values intramedullary tension [13], it ranged between 0.60 and 1.30 in the basal studies (mean $\pm \mathrm{SD}, 0.84 \pm 0.24$ ) and between 0.13 and 0.68 (mean \pm SD, $0.33 \pm 0.19$ ) at the end of the study $(P=0.003)$. Figure 3 shows syrinx changes after cell therapy. Additional information is provided in the Supplementary Material (Supplementary Table S3 and Supplementary Figure 6).

\section{Summary of clinical improvements}

Table XII summarized the improvements obtained in the patients of the study. All of the patients showed variable improvement in clinical scales, mainly in the

Table VI. Scores in VAS scale.

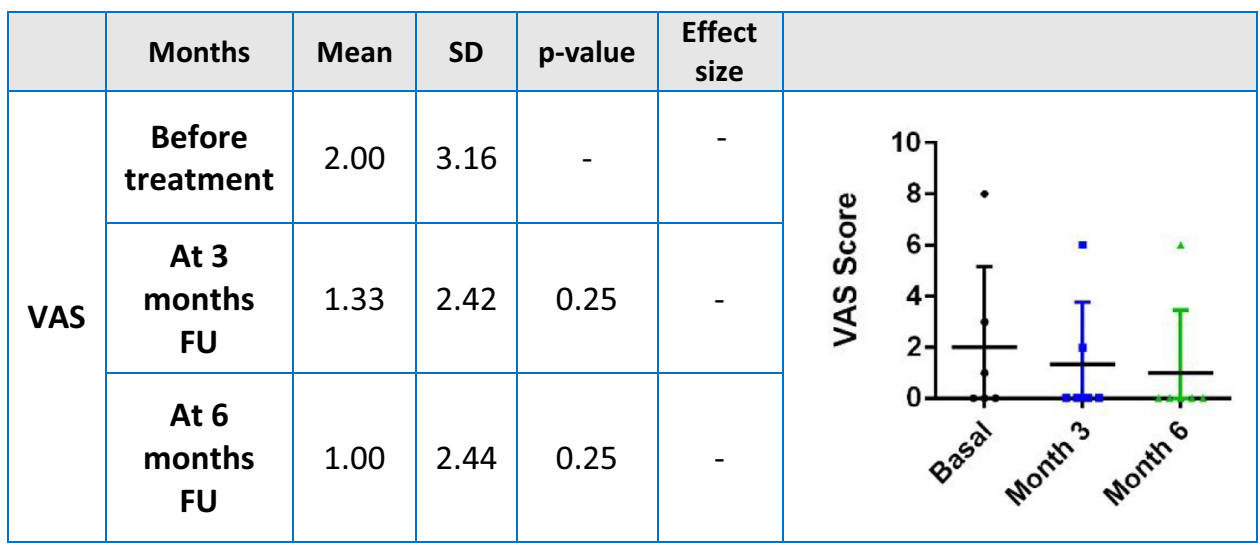

Wilcoxon test was applied comparing each month with baseline. Tendency to improvement was observed but without statistical significance. 
Table VII. Scores in Geffner scale.

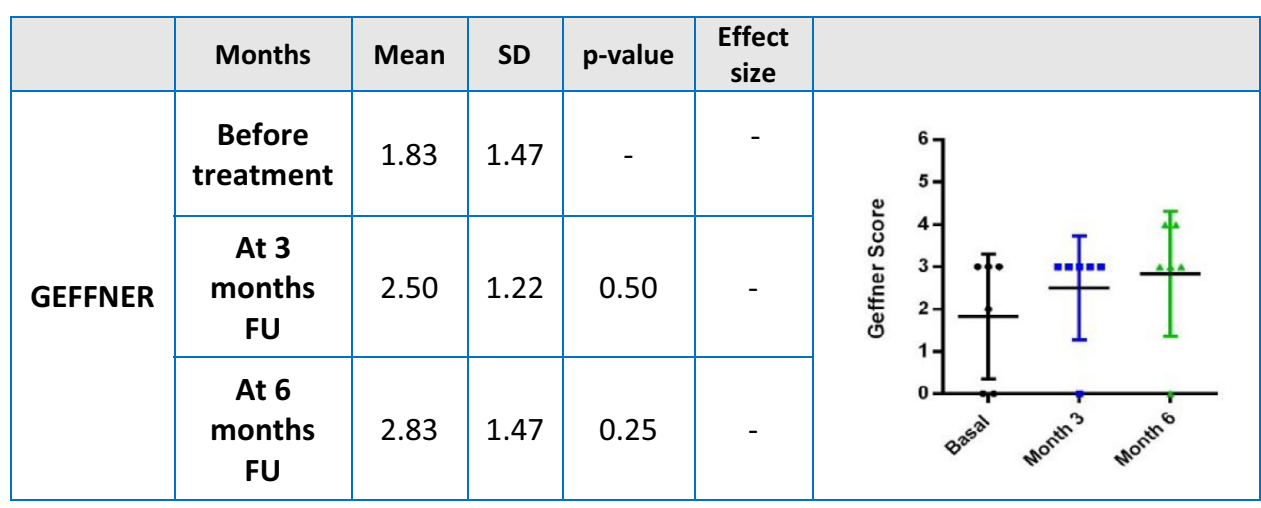

Wilcoxon test was applied comparing each month with baseline. Tendency to improvement was observed but without statistical significance.

Table VIII. Scores in NBD scale.

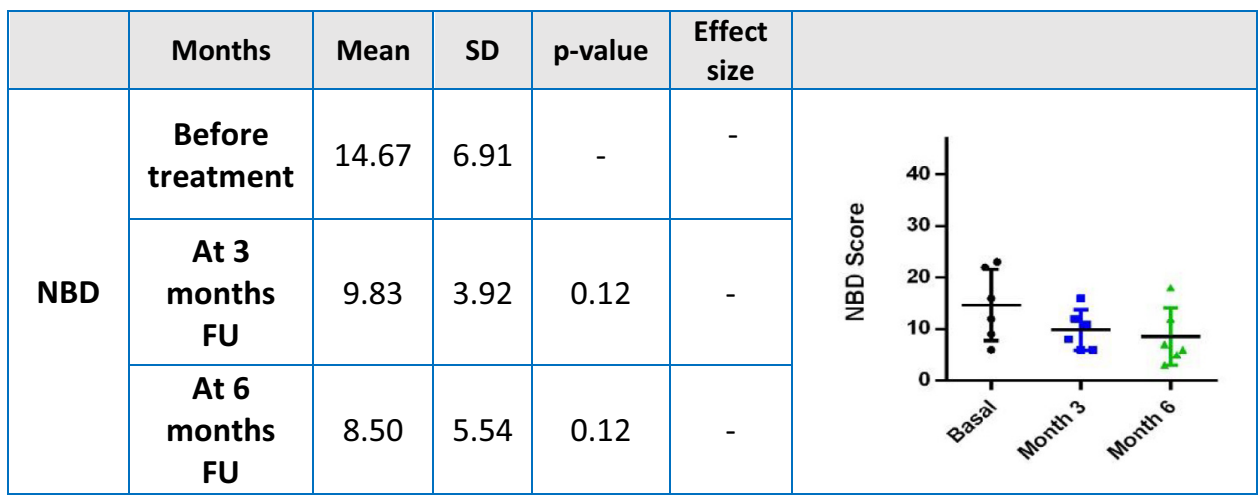

Wilcoxon test was applied comparing each month with baseline. Tendency to improvement was observed but without statistical significance.

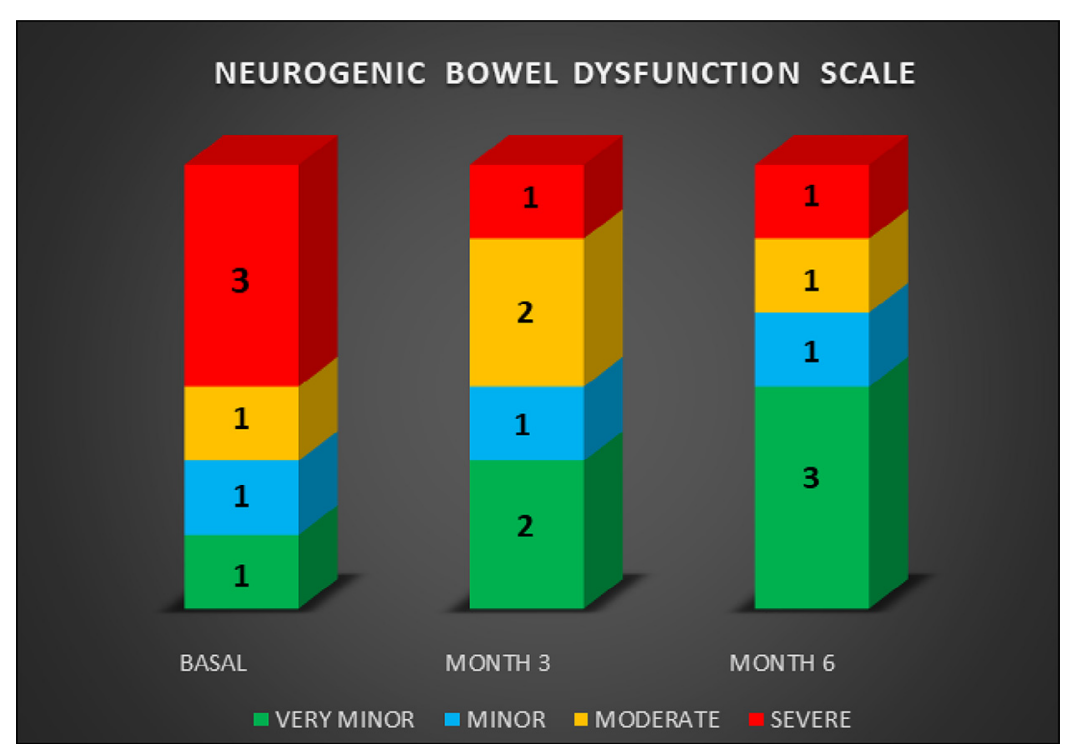

Figure 2. Improvement in NBD throughout the study. Previous to cell therapy, three patients had a severe NBD, and at the end of the study only one patient had a severe NBD. 
Table IX. Improvement for each patient obtained in parameters of ano-rectal manometry.

\begin{tabular}{lcccccc}
\hline Patient code & 01 & 02 & 03 & 04 & 05 & 06 \\
\hline $\begin{array}{c}\text { Increase in mean pressure } \\
\text { of rectal sphincter in rest }\end{array}$ & No & Yes & No & No & Yes & No \\
$\begin{array}{c}\text { Increase in mean pressure } \\
\text { of anal contraction }\end{array}$ & Yes & Yes & Yes & No & Yes & No \\
$\begin{array}{c}\text { Improvement in first } \\
\text { sensation of rectal filling }\end{array}$ & No & Yes & Yes & No & Yes & No \\
\hline
\end{tabular}

Table X. Improvement for each patient obtained in urodynamic parameters.

\begin{tabular}{|c|c|c|c|c|c|c|}
\hline Patient code & 01 & 02 & 03 & 04 & 05 & 06 \\
\hline $\begin{array}{l}\text { Improvement in first } \\
\text { sensation at filling }\end{array}$ & Yes & No & Yes & Yes & No & Yes \\
\hline $\begin{array}{l}\text { Increase in bladder } \\
\text { capacity at filling }\end{array}$ & No & Yes & No & Yes & Yes & Yes \\
\hline $\begin{array}{l}\text { Decrease in detrusor } \\
\text { pressure at filling }\end{array}$ & No & Yes & Yes & No & Yes & No \\
\hline $\begin{array}{l}\text { Improvement in bladder } \\
\text { compliance at filling }\end{array}$ & No & Yes & Yes & No & Yes & No \\
\hline $\begin{array}{l}\text { Decrease in postmictional } \\
\text { residue }\end{array}$ & Yes & No & Yes & Yes & Yes & No \\
\hline
\end{tabular}

Table XI. Improvement for each patient obtained in neurophysiological parameters.

\begin{tabular}{lcccccc}
\hline Patient code & 01 & 02 & 03 & 04 & 05 & 06 \\
\hline $\begin{array}{l}\text { Improvement in SSEP } \\
\text { Improvement in MEP }\end{array}$ & No & Yes & No & Yes & No & No \\
$\begin{array}{l}\text { Improvement in sensitivity } \\
\text { conduction }\end{array}$ & No & No & No & Yes & Yes & No \\
$\begin{array}{c}\text { Improvement in motor } \\
\text { conduction }\end{array}$ & No & No & No & Yes & No & No \\
$\begin{array}{c}\text { Improvement in voluntary } \\
\text { muscle contraction }\end{array}$ & No & No & No & No & Yes & No \\
$\begin{array}{c}\text { Presence of infralesional } \\
\text { active muscle } \\
\text { reinnervation }\end{array}$ & No & No & No & No & Yes & Yes \\
\hline
\end{tabular}

scales related to sphincter dysfunction and neuropathic pain.

\section{Discussion}

It is well known that between $1 \%$ and $4.45 \%$ of paraplegic patients can develop in a late phase large intramedullary cavities extending several segments at distance from the area of SCI, which is known as "posttraumatic syringomyelia" or "post-traumatic cystic myelopathy". The syringomyelic cavity may be asymptomatic or associated with a worsening of previously established neurological deficit, such as development of supralesional sensory disorders, autonomic dysreflexia or increase of neuropathic pain or spasticity [14-19]. At present, there is no evi- dence that the drainage of these cavities provides benefit, and surgery is recommended only in paraplegic patients with post-traumatic syringomyelia who developed worsening of symptoms, which were associated with an enlargement of previous intramedullary cavities $[15,17]$. Various surgical techniques, such as subarachnoid-peritoneal shunt, subarachnoidsubarachnoid bypass or arachnolysis with untethering and duraplasty at the level of underlying trauma, have been used in post-traumatic syringomyelia [17]. Because shunting exposed the patients to a higher rate of clinical recurrence and reoperation, at present, duraplasty and arachnolysis seem to be the most widely accepted treatment, but with doubtful long-term benefit.

On the other hand, cell therapy with MSCs seems to provide new promise for patients with SCI and it is necessary to know the selection of patients who can get benefit from these new techniques [20]. We have recently described how a paraplegic patient who received surgical administration of MSCs in the SCI zone improved in the ASIA assessment and in sphincter control, and, at the same time, an associated supralesional syrinx was reduced [21]. Due to the experience obtained with said patient, the present clinical trial was designed to study if patients with large syringomyelic cavities should be submitted to cell therapy, hoping for some kind of benefit. Although the limited follow-up and the small number of patients can be clear limitations of the present study, our previous experience shows that, after cell therapy in patients with SCI, the clinical benefit, mainly in sensitive improvement, is observed in the course of the first 2 months after MSC administration. For this reason only a short follow-up period was chosen. Similarly, only six patients were chosen for the study because this number of patients was considered sufficient to know a posible individual benefit or a trend toward a benefit, although we did not expect to obtain improvements with statistical significance.

The analysis of our present findings shows the safety and feasibility of intrathecal administration of MSCs in post-traumatic syringomyelia, obtaining diverse individual improvement in the few patients studied. In comparison with previous studies of cell therapy in chronic paraplegic patients $[1,2]$, the scarce response to treatment in scores of sensitivity is strange. It can be explained by the presence of a sustained intramedullary tension due to syrinx, which determines an atrophy of the spinal cord, as it can be seen in our patients when the reduction of the syrinx after cell therapy allows a correct identification of the cord. On the other hand, the progressive tendency to improvement obtained in the IANR-SCIFRS, Penn, Ashworth, Geffner, VAS and NBD scales is similar to the tendency to improvement showed in 
clinical trials that used intrathecal cell therapy in paraplegic patients [2].

It is difficult to explain the fact that after administration of MSCs in the syrinx, without aspirating its content, syrinx reduction can be obtained, suggesting that after cell therapy a redistribution of cerebrospinal fluid is achieved. When syrinx is reduced, a thinned spinal cord is frequently observed, and, considering that an atrophied spinal cord is associated with poor response to cell therapy [22], if cell therapy is considered for post-traumatic syringomyelia, it should be done early before intramedullary pressure can cause or increase the atrophy of the injured spinal cord. In
Table XII. Clinical improvement for each patient obtained at the end of the follow-up.

\begin{tabular}{|l|l|l|l|l|l|l|}
\hline CODE PATIENT & 01 & 02 & 03 & 04 & 05 & 06 \\
\hline AIS grade & A & A & D & B & B & A \\
\hline Sensitivity & & & & & & \\
\hline Global SC function & & & & & & \\
\hline Spasms & & & & & & \\
\hline Spasticity & & & & & & \\
\hline Neuropathic pain & & & & & & \\
\hline Bowel dysfunction & & & & & & \\
\hline Bladder dysfunction & & & & & & \\
\hline
\end{tabular}

Green: Patients who improve. Yellow: Patients who neither improve nor worsen.

SC, spinal cord.
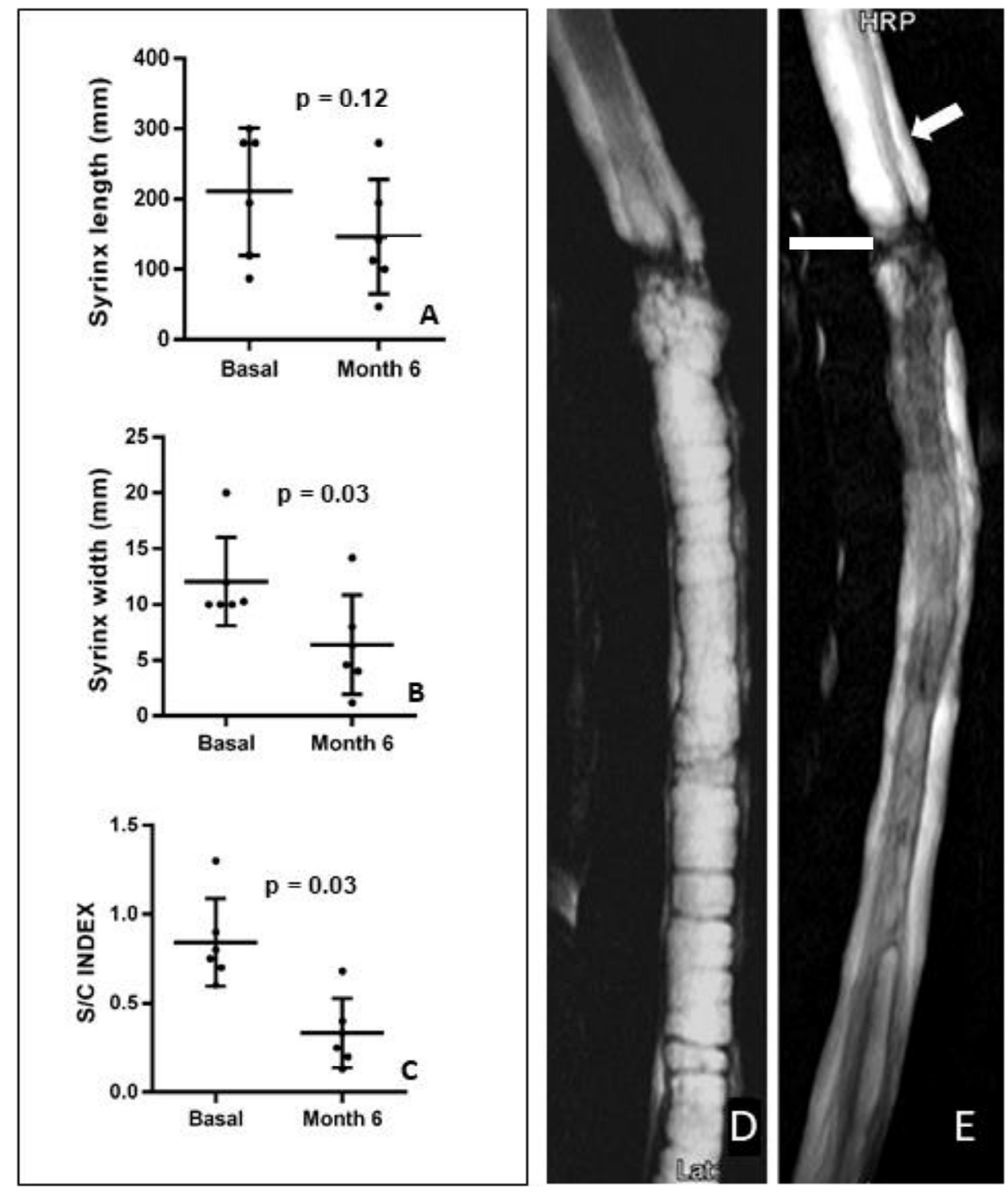

Figure 3. Syrinx changes after cell therapy. (A, B and C) Graphs with the improvements in the syrinx size. Statistical significance was obtained after cell therapy for the syrinx width and for $\mathrm{S} / \mathrm{C}$ index $(P=0.03)$. (D and E) Changes obtained in the syrinx in patient 06 . (D) MR-myelography previous to cell therapy, showing the SCI at D5 vertebral level (bar) and an extensive syrinx, mainly at infralesional levels. (E) Changes in the syrinx at the end of the follow-up. Spinal cord is now identified, and at supralesional level a thinned spinal cord can be seen, with increased subarachnoid space (arrow). 
our patients, individual improvements were also observed in the studies of urodynamic, neurophysiology, neuroimaging and ano-rectal manometry. These improvements can be observed previous to clinical improvements, and they support a possible benefit of the cell therapy.

\section{Conclusions}

In conclusion, in paraplegic patients with posttraumatic syringomyelia, the administration within the syrinx of a single dose of 300 million autologous MSCs supported in autologous plasma is safe. It can reduce syrinx and provide individual benefits. In any case, new studies with a greater number of cases are required.

\section{Acknowledgments}

The present clinical trial was mainly supported by the Mapfre and Rafael del Pino Foundations. Additional support was obtained from the Atresmedia Foundation and the APINME Association. We extend special thanks to Sermes CRO for help during the development and analysis of the present study, and we especially appreciate the cooperation of the Neurological Cell Therapy Group from the Puerta de HierroMajadahonda-Hospital (listed in the Supplementary Material).

Disclosure of interests: The authors have no comercial, proprietary or financial interest in the products or companies described in this article.

\section{References}

[1] Vaquero J, Zurita M, Rico MA, Bonilla C, Aguayo C, Montilla $\mathrm{J}$, et al. An approach to personalized cell therapy in chronic complete paraplegia: the Puerta de Hierro phase I/II clinical trial. Cytotherapy 2016;18:1024-35.

[2] Vaquero J, Zurita M, Rico MA, Bonilla C, Aguayo C, Fernández C, et al. Repeated subarachnoid administrations of autologous mesenchymal stromal cells supported in autologous plasma improve quality of life in patients suffering incomplete spinal cord injury. Cytotherapy 2017;19:34959.

[3] Frisch SM, Francis H. Disruption of epithelial cell-matrix interactions induces apoptosis. J Cell Biol 1994;124:619-26.

[4] World Medical Association Declaration of Helsinki. Ethical principles for medical research involving human subjects. JAMA 2000;284:3043-5.

[5] International Conference on Harmonisation Expert Working Group. ICH 17 armonized tripartite guideline: guideline for good clinical practice. June, 10, 1996. Available from: http:// www.ich.org/fileadmin/Public_Web_Site/ICH_Products/ Guidelines/Efficacy//E6/E6_R1_Guideline.pdf.
[6] Kirshblum SC, Burns SP, Biering-Sorensen F, Donovan W, Graves DE, Jha A, et al. International standards for neurological classification of spinal cord injury (revised 2011). J Spinal Cord Med 2011;34:535-46.

[7] International Association of Neurorestoratology. Spinal cord injury functional rating scale. Zhongguo Xiu Fu Chong Jian Wai KeZaZhi 2008;22:1021-3.

[8] Woodforde JM, Merskey H. Some relationship between subjective measures of pain. J Psychosom Res 1972;16: 173-8.

[9] Penn RD, Savoy SM, Corcos D, Latash M, Gottlieb G, Parke $\mathrm{B}$, et al. Intrathecal baclofen for severe spinal spasticity. $\mathrm{N}$ Engl J Med 1989;320:1517-21.

[10] Bohannon RW, Smith MB. Interrater reliability of a modified Ashworth scale of muscle spasticity. Phys Ter 1987;67: 206-7.

[11] Geffner LF, Santacruz P, Izurieta M, Flor L, Maldonado B, Auad $\mathrm{AH}$, et al. Administration of autologous bone marrow stem cells into spinal cord injury patients via multiple routes is safe and improves their quality of life: Comprehensive case studies. Cell Transplant 2008;17:1277-93.

[12] Krogh K, Christensen P, Sabroe S, Laurberg S. Neurogenic bowel dysfunction score. Spinal Cord 2006;44:625-31.

[13] Vaquero J, Martínez R, Arias A. Syringomyelia-Chiari complex: magnetic resonance imaging and clinical evaluation of surgical treatment. J Neurosurg 1990;73:64-8.

[14] Schurch B, Wichmann W, Rossier AB. Post-traumatic syringomyelia (cystic myelopathy): a prospective study of 449 patients with spinal cord injury. J Neurol Neurosurg Psychiatry 1996;60:61-7.

[15] Klekamp J, Samii M. Syringomyelia associated with diseases of the spinal canal. In: Syringomyelia: Diagnosis and Treatment. Italy, Berlin: Springer-Verlag; 2002.

[16] Brodbelt AR, Stoodley MA. Post-traumatic syringomyelia. A review. J Clin Neurosci 2003;10:401-8.

[17] Klekamp J. Treatment of posttraumatic syringomyelia. J Neurosurg Spine 2012;17:199-211.

[18] Karam Y, Hitchon PW, Mhanna NE, He W, Noeller J. Post-traumatic syringomyelia: outcome predictors. Clin Neurol Neurosurg 2014;124:44-50.

[19] Krebs J, Koch HG, Hartmann K, Frotzler A. The characteristics of posttraumatic syringomyelia. Spinal Cord 2016;54:463-6.

[20] Vaquero J, Zurita M. Cell transplantation in paraplegic patients: the importance of properly assessing the spinal cord morphology. Clin Transplant 2013;27:968-71.

[21] Vaquero J, Hassan R, Fernández C, Rodríguez-Boto G, Zurita $M$. Cell therapy as a new approach to the treatment of posttraumatic syringomyelia. World Neurosurg 2017;107:1047, e5-1047.e8.

[22] Vaquero J, Zurita M, Rico MA, Aguayo C, Fernández C, Gutiérrez R, et al. Intrathecal administration of autologous bone marrow stromal cells improves neuropathic pain in patients with spinal cord injury. Neurosci Lett 2018;670:1418.

\section{Appendix: Supplementary material}

Supplementary data to this article can be found online at doi:10.1016/j.jcyt.2018.04.006. 